\title{
El componente demográfico de las necesidades habitacionales urbanas en América Latina: el caso de Buenos Aires*
}

\author{
Mariana Marcos \\ Universidad Nacional de Tres de Febrero, Argentina \\ mmarcos@conicet.gov.ar

\section{Juan A. Módenes} \\ Universitat Autònoma de Barcelona. Centre d'Estudis Demogràfics \\ y Departamento de Geografía \\ jamodenes@ced.uab.es
}

Universidad de Buenos Aires. Instituto de Investigaciones Gino Germani, CONICET -

\section{Resumen}

El artículo tiene por objetivo poner en primer plano el componente demográfico de las necesidades habitacionales —o demanda demográfica de viviendas - y sus interacciones con la calidad del parque habitacional y la dinámica del mercado inmobiliario en contextos urbanos de América Latina. Para ello se realiza una propuesta metodológica que se aplica a la Región Metropolitana de Buenos Aires, un caso rico en complejidad y heterogeneidad interna. Las proyecciones de hogares se llevan a cabo mediante el método de tasa de jefatura, y se vinculan con el déficit habitacional a escala municipal a través de técnicas de análisis espacial. Como resultado, se proponen tres escenarios de planificación en función de la calidad del parque habitacional y las condiciones demográficas para la rotación de las viviendas (según los flujos de creación y disolución de hogares estimados), que se analizan en relación con las particularidades de la dinámica del mercado inmobiliario en cada contexto.

Palabras clave: demanda demográfica de vivienda; proyecciones de hogares; planificación territorial

* Este artículo se inscribe en los proyectos $\mathrm{I}+\mathrm{D}+\mathrm{I}$ «Comportamientos demográficos y estrategias residenciales: apuntes para el desarrollo de nuevas políticas sociales» (CSO201679142-R, España), «Desigualdades microespaciales urbanas» (32/375 A, UNTREF, Argentina) y «Desigualdades intraurbanas y salud» (PIP 11220170100166CO, CONICET, Argentina). Se agradece el apoyo del Centre d'Estudis Demogràfics (CERCA Programme / Generalitat de Catalunya) y el Programa de financiamiento parcial para estadías en el exterior para investigadores asistentes del CONICET, y los valiosos comentarios de Juan Pablo del Río y Victoria Mazzeo. 
Resum. El component demogràfic de les necessitats urbanes d'habitatge a l'Amèrica Llatina: el cas de Buenos Aires

L'article té per objectiu donar rellevància al component demogràfic de les necessitats residencials - o demanda demogràfica d'habitatge - $\mathrm{i}$ les seves interaccions amb la qualitat del parc existent d'habitatges i la dinàmica del mercat immobiliari en contextos urbans de l'Amèrica Llatina. Amb aquesta finalitat es realitza una proposta metodològica que s'aplica a la Regió Metropolitana de Buenos Aires, un cas ric en complexitat i heterogeneïtat interna. Les projeccions de llars es porten a terme mitjançant el mètode de taxa de principalitat de la llar, i es vinculen amb el dèficit d'habitatges a escala municipal a través de tècniques d'anàlisi espacial. Com a resultat, es proposen tres escenaris de planificació sobre la base de la qualitat del parc habitacional i de les condicions demogràfiques per a la rotació dels habitatges (segons els fluxos de creació i dissolució de llars estimats). Finalment, els tres escenaris s'analitzen en relació amb la dinàmica del mercat immobiliari en cada context local.

Paraules clau: demanda demogràfica d'habitatge; projeccions de llars; planificació territorial

Résumé. La composante démographique des besoins de logements dans les villes d'Amérique latine : le cas de Buenos Aires

L'article vise à mettre en évidence la composante démographique des besoins de logement - ou demande démographique de logement - et ses interactions avec la qualité du parc de logements et la dynamique du marché immobilier dans les contextes urbains en Amérique Latine. Pour cela, une proposition méthodologique est faite qui est appliquée à la Région métropolitaine de Buenos Aires, un cas riche en complexité et en hétérogénéité interne. Les projections des ménages sont faites en utilisant la méthode du taux de personne de référence et elles sont corrélées au déficit de logements au niveau communal grâce à des techniques d'analyse spatiale. À la suite de la recherche, trois scénarios de planification sont proposés en fonction de la qualité du parc de logements et des conditions démographiques de rotation des logements (à partir des flux estimés de création et de dissolution des ménages). Ces trois scénarios sont analysés en fonction des particularités de la dynamique du marché immobilier dans chaque contexte local.

Mots-clés : demande démographique de logements; projections des ménages; aménagement du territoire

Abstract. The demographic component of urban housing needs in Latin America: The case of Buenos Aires

This article aims to bring to the forefront the demographic component of housing needs - or demographic housing demand - and its interactions with the quality of housing stock and the dynamics of the real estate market in Latin American urban contexts. A methodological proposal is made and applied to the Metropolitan Region of Buenos Aires, a case rich in complexity and internal heterogeneity. Household projections are carried out using the headship rate method and linked to housing needs at the municipal level using spatial analysis techniques. As a result, three planning scenarios are proposed on the basis of the quality of housing stock and the demographic determination for housing rotation (according to the estimated flows of household creation and dissolution), which are analyzed in relation to the real estate market dynamics in each context.

Keywords: demographic housing demand; household projections; planning 


\section{Sumario}

1. Introducción: previsiones demográficas de demanda de vivienda en contextos de déficit estructural

2. Discusión teórica sobre el concepto de necesidades de vivienda

3. El caso de estudio: Buenos Aires
4. Aportación metodológica para analizar la demanda demográfica de vivienda en grandes ciudades

5. Aplicación al caso de la Región Metropolitana de Buenos Aires

6. Reflexiones finales

Referencias bibliográficas

\section{Introducción: previsiones demográficas de demanda de vivienda en contextos de déficit estructural}

En el año 1979, en el marco de su análisis del problema de la vivienda como dimensión de un proceso de desarrollo desequilibrado en América Latina, Ratinoff (1979) advertía que debían adoptarse medidas «radicales» para resolver los problemas de calidad y cantidad de viviendas, de lo contrario, se incrementarían por las perspectivas demográficas de entonces: población en aumento y un incremento todavía mayor de los hogares, que, cada vez más pequeños, ejercerían mayor presión sobre el ya deficiente e insuficiente parque de viviendas. Este mismo diagnóstico había sido llevado a la Conferencia de Vancouver en 1976, donde las ciudades fueron objeto de una gran preocupación, ya que en previsión del aumento de la urbanización se consideraba que iban a ser el epicentro del problema (CEPAL, 1996).

Desde entonces, los esfuerzos de los países en materia de necesidades habitacionales estuvieron influidos por los avatares macroeconómicos y políticos de la región. Hacia el año 2006, el déficit habitacional se había reducido en términos relativos, pero sin que menguaran los stocks de hogares y viviendas afectados. Mientras tanto, la cantidad de hogares seguía creciendo en contextos urbanos de profunda desigualdad, a razón de 6 millones de nuevos hogares urbanos al año (Rojas y Medellín, 2011).

Las necesidades habitacionales tienen carácter compuesto, dado que existe una dimensión temporal actual del déficit habitacional (o dimensión social) y una dimensión temporal futura del crecimiento de la cantidad de hogares que demandarán vivienda (o dimensión demográfica), y ambos componentes siguen teniendo una crucial relevancia en las ciudades latinoamericanas. Sin embargo, la producción de conocimiento sobre el tema en la región se ha centrado fundamentalmente en el déficit habitacional presente. La mayoría de los institutos nacionales de estadística siguen sin hacer proyecciones de hogares (Yépez et al., 2012b), y el abordaje académico de la dimensión demográfica del problema ha privilegiado la escala regional y nacional, con excepciones enfocadas en el nivel meso, que son importantes antecedentes de este trabajo (Givisiez y Olivera, 2005; Macedo et al., 2005; Lodoño, 2017; Aparicio y Brusse, 2018).

En este marco, el artículo se propone poner en primer plano el componente demográfico de las necesidades habitacionales —o demanda demográfica de 
viviendas - y sus interacciones con la calidad del parque habitacional y la dinámica del mercado inmobiliario en contextos urbanos, de cara a la proposición de escenarios territoriales de planificación. Para ello, se realiza una propuesta metodológica que se aplica al caso de la Región Metropolitana de Buenos Aires (RMBA), una de las principales áreas metropolitanas de América Latina, que destaca por su riqueza en términos de complejidad y heterogeneidad interna. En particular, se pone el foco en las proyecciones anuales de hogares para la escala municipal (horizonte de 2025) y las heterogeneidades territoriales, que son las dimensiones del problema que han estado más desatendidas hasta la actualidad.

\section{Discusión teórica sobre el concepto de necesidades de vivienda}

En muchos trabajos anglosajones, el concepto de necesidades de vivienda se refiere a las viviendas cuyo acceso debe ser garantizado mediante ayudas públicas cuando los hogares no pueden acceder a ellas por sí solos (Bramley et al., 2010), y se utiliza para distinguir a la vivienda social de la provista por el mercado privado (King, 2009). Aquí se adopta una definición más amplia que incluye la vivienda de calidad requerida para albergar a la totalidad de la población, y no solo a la que no logra acceder por sus propios medios. Según Myers, Pitkin y Park (2002: 567), las necesidades de vivienda se definen como «the number and type of housing units required to accommodate a population at a given standard of housing occupancy».

Desde la perspectiva de las necesidades, las viviendas se evalúan y proyectan a partir de criterios o umbrales normativos de habitabilidad y adecuación a la estructura de los hogares definidos de forma externa, y sin considerar la capacidad económica de los hogares (King, 2009) —lo cual es tan útil para la cuantificación del problema y la planificación de soluciones como controvertido por lo acotado de la mirada sobre un fenómeno multidimensional (Gilbert, 2000)_, por lo tanto, deben diferenciarse de los «sentimientos» o percepciones de necesidad y de la «demanda» efectiva (Bradshaw, 1972, citado en King, 2009; Chombart de Lauwe, 1976; Leal y Cortés, 1995) que resulta de la combinatoria de percepciones de necesidad, estrategias residenciales y elecciones.

Myers, Pitkin y Park (2002) precisan que las necesidades de vivienda incluyen dos dimensiones temporales: 1) el «déficit actual», o necesidades «sociales» de vivienda, definidas por condiciones habitacionales que no cumplen con un estándar normativo de características físicas de la vivienda y de adecuación entre hogares y viviendas; y 2) las «necesidades de construcción futuras», cuyo volumen y características vienen dados por las previsiones de crecimiento de la población y de evolución de los arreglos residenciales y los estándares residenciales normativos.

Para medir el déficit actual es preciso establecer umbrales normativos consensuados. En América Latina, los trabajos del Centro Latinoamericano y Caribeño de Demografía (Celade) (Celade, 1996; Rodríguez, 1999; Arriagada, 2005) ayudaron a establecer los umbrales normativos actuales considerando la materialidad de la vivienda, el espacio disponible para los hogares en las viviendas, la provisión de servicios básicos y el allegamiento (cohabitación de 
unidades domésticas) para distinguir un componente cualitativo del déficit (viviendas a mejorar o ampliar) y uno cuantitativo (viviendas a construir para los hogares y núcleos familiares allegados por necesidad y para reemplazar las irrecuperables). Esto es imprescindible cuando la realidad desborda las herramientas teórico-metodológicas concebidas en los países desarrollados, y debe continuar revisándose — en particular, qué protagonismo se le da a la informalidad y qué significado tiene la cohabitación de hogares y núcleos familiares en diferentes sectores sociales- (Macedo, 2010).

Las necesidades futuras de vivienda suelen estudiarse a través de la demanda demográfica, que es la necesidad de nuevas viviendas por el aumento de los hogares que se deriva de la dinámica demográfica de la población (Givisiez y Oliveira, 2005), esto es, de su crecimiento y de la evolución de su estructura por edad y de las tasas de principalidad de hogar específicas por edad (Hugo, 2005) —o propensión al consumo de vivienda a cada edad (Pitkin y Myers, 1994) — Ello a pesar de que, en la dimensión temporal futura, necesidad y demanda de vivienda tampoco son equivalentes. En particular, el componente demográfico de las tasas de jefatura es muy sensible a factores como las tasas de interés, las políticas de vivienda, la asequibilidad de la vivienda y la coyuntura económica y su impacto en los ingresos (Hugo, 2005; Bramley et al., 2010; Aparicio y Brusse, 2018), que median entre necesidades, sentimientos de necesidad y demanda a través de las estrategias residenciales. No obstante, el elemento individual de mayor influencia en la conformación de la demanda de nuevas viviendas es el número de hogares, y cuando se trata de brindar herramientas para la planificación, en especial a largo plazo, la demografía tiene mucho que ofrecer (Belsky, 2009). En cambio, los factores restrictivos del tipo extrademográfico son difíciles de estimar desde el laboratorio de producción de datos estadísticos, pero pueden traerse a colación al pasar de la escala macro a la local (Murdoch, 2000) para delinear escenarios de planificación.

\section{El caso de estudio: Buenos Aires}

La RMBA se define aquí como la suma del área central compuesta por la Ciudad Autónoma de Buenos Aires (CABA) y 40 municipios circundantes. Las dos coronas de municipios más próximos a la CABA conforman lo que se conoce como «24 Partidos del Gran Buenos Aires», puesto que sobre ellos se despliega la mayor parte del área urbana más grande del país: la aglomeración Gran Buenos Aires ${ }^{1}$. La tercera corona está conformada por 16 municipios que en su mayoría contienen aglomeraciones independientes más pequeñas, muy influenciadas por la proximidad con la principal $^{2}$.

1. Aglomeración designa el «área comprendida por una envolvente que rodea, en toda su extensión, una mancha urbana continua» (INDEC, 1999: 2).

2. La definición adoptada es coherente con el concepto de metrópolis-región, que denomina a «verdaderos archipiélagos urbanos de fronteras difusas» (Mattos, 1998: 723) e incluye espacios vacíos o semivacíos particularmente dinámicos en las últimas décadas. 
Según el último censo de 2010, la RMBA concentra 14.839 .026 personas (el $37 \%$ de la población argentina) en una superficie ${ }^{3}$ de $11.434 \mathrm{~km}^{2}$. Del total de personas, 14.694.202 conforman los 4.704.569 hogares particulares empadronados en 4.316 .210 viviendas particulares.

Buena parte de ese parque habitacional presenta problemas de calidad constructiva y dotación de servicios de distinto nivel de severidad, que impactan de forma negativa en las condiciones de vida de la población, en especial en áreas periféricas. Esta difícil situación habitacional y su configuración espacial se originan en el desarrollo histórico de la expansión de la ciudad. Mientras se dio en el interior de la actual CABA, logró integrar los nuevos suburbios populares a la ciudad central mediante la parcelación previa de las tierras, la organización de los vecinos y la dotación de infraestructura urbana. La expansión pasó a ser deficiente cuando se extendió a tierras de la provincia de Buenos Aires, donde las distancias y extensiones comenzaron a ser mayores y la planificación y los recursos menguaron (Gorelik, 2009) ${ }^{4}$.

Los actuales institutos de la vivienda de la provincia de Buenos Aires y la CABA tuvieron su origen en organismos creados en las décadas de 1950 y 1960, respectivamente. Para paliar el déficit habitacional a escala nacional, en 1972, se creó el Fondo Nacional de la Vivienda (Realini et al., 2018), en plena industrialización del país y desarrollo del estado de bienestar (Torrado, 2010). En aquel momento, la aglomeración Gran Buenos Aires casi alcanzaba su tamaño actual, y la dimensión y la estructura espacial del déficit habitacional estaban consolidadas. Este problema no se ha solucionado desde entonces por falta de medios, y la escasez de datos oficiales sobre el tema —incluidas las proyecciones de hogares - debe interpretarse en ese marco. Según Di Virgilio y Rodríguez (2018), el déficit habitacional en 2014-2015 se componía de un déficit cualitativo del 29\% (1.147.000 viviendas, aproximadamente, requieren mejoras o ampliaciones) y de la necesidad de construir viviendas nuevas (déficit cuantitativo) para aproximadamente 390.000 hogares que residen en espacios de materialidad irrecuperable o comparten la vivienda por necesidad (presunta) ${ }^{5}$.

En la actualidad, el déficit habitacional se combina con un mercado inmobiliario restrictivo para el acceso a una vivienda formal. Tras la crisis de 20012002, se inició un nuevo ciclo alcista de los precios del suelo, aun cuando

3. No considera sector insular (delta del Paraná).

4. La actual CABA fue territorio (y tuvo presupuesto) nacional hasta el año 1994, cuando la reforma de la Constitución nacional le otorgó el estatus de ciudad autónoma y la equiparó a una provincia.

5. La metodología que siguen las autoras (Celade, 1996: 18) establece que hay consenso en que los hogares secundarios constituyen demanda insatisfecha de vivienda, pero los núcleos familiares secundarios no siempre, puesto que pueden encontrarse allegados al núcleo primario por conveniencia o por restricciones de distinto tipo (que las fuentes de datos tradicionales no permiten conocer). Existen otras estimaciones realizadas con metodologías distintas, como las del Ministerio de Planificación Federal, Inversión Pública y Servicios (2015) y Vergara Parra (2017). 
la oferta residencial se ha expandido, tanto por iniciativa privada como del Estado (Baer y Kauw, 2016). Según Baer y Kauw (2016), el aumento de precios ha sido generalizado en la RMBA, pero todavía más en las áreas antes más accesibles. Aunque la heterogeneidad espacial intrametropolitana de precios del suelo se ha reducido, sigue su tradicional patrón, que coincide con la estructura socioespacial de la Región: descenso desde el centro hacia la periferia y desde los ejes de crecimiento y subcentros bien comunicados hacia los intersticios; precios más altos en el norte por encima del oeste y el sur, y enclaves de riqueza en los barrios cerrados de la periferia.

Con la crisis económica actual, los hogares han perdido capacidad económica, la moneda nacional se ha devaluado constantemente - cuando el mercado de compraventa de viviendas está dolarizado-y las exorbitantes tasas de interés han cerrado la opción del crédito. Con ello, para muchas familias, se prolonga su endeudamiento hipotecario, se ven impedidas de pagar las cuotas o de intentar acceder a la propiedad de la vivienda; $y$, para otras, implica renunciar a metros cuadrados o localización, o incluso caer en la informalidad (Baer et al., 2018).

Mientras tanto, según Rojas y Medellín (2011: 17), en el país se están creando 214.000 hogares al año y, aunque hasta ahora no se disponía de proyecciones de hogares para la RMBA, las de población permiten abonar la hipótesis de que en los próximos años la demanda demográfica de viviendas será intensa (Marcos y Chiara, 2019).

\section{Aportación metodológica para analizar la demanda demográfica de vivienda en grandes ciudades}

Según Hugo (2005), el crecimiento de la cifra de hogares responde a tres mecanismos demográficos: el «crecimiento» de la población, el cambio en la «estructura» por edad de la población y la dinámica de las «propensiones a formar hogar» en cada edad (tasas de jefatura ${ }^{6}$ ). En poblaciones que cuentan todavía con un importante crecimiento demográfico (países en plena transición demográfica o ciudades con alta inmigración), este es el principal motor del crecimiento de los hogares y las necesidades residenciales futuras. Sin embargo, conforme el crecimiento demográfico tiende a estabilizarse, cobran más importancia relativa los cambios en la estructura (tendencia al envejecimiento) y los altibajos en el comportamiento de formación de hogares por edad (ligado a las coyunturas socioeconómicas). Toda proyección de hogares tiene en cuenta de alguna manera los tres componentes. Al comparar los resultados de ediciones sucesivas de proyecciones de hogares para los Estados Unidos, McClue (2018) muestra cómo pequeños cambios temporales en dichos componentes impactan significativamente sobre el crecimiento previsto de los hogares. En el caso de las poblaciones latinoamericanas, los tres

6. Utilizaremos aquí el término más usado en Argentina de jefatura como equivalente a principalidad, "persona de referencia», empleado actualmente en otros contextos. 
componentes son muy dinámicos (Givisiez y Oliveira, 2005), lo que se espera que se reproduzca en el caso de Buenos Aires. De ahí la necesidad de tener especial cuidado con el uso de metodologías adecuadas y la incorporación de hipótesis de cambio en las tres dimensiones.

\subsection{Método y fuentes}

Yépez (2011) clasifica los diferentes métodos de proyección de hogares en dinámicos y estáticos, según estudien el comportamiento de cohortes a través del tiempo o comparen la distribución de la población y los atributos del hogar en determinados momentos.

La proyección de los hogares se realiza aquí mediante el método de tasa de jefatura, que se encuentra entre los métodos estáticos y es uno de los más utilizados. Consiste en aplicar la proporción proyectada de población que es persona de referencia o jefe de hogar ${ }^{7}$ a la población proyectada para obtener el número de hogares en sucesivos años (United Nations, 1973).

La tasa de jefatura y los hogares proyectados se calculan, respectivamente, mediante las siguientes fórmulas, que se aplican al universo de personas de 15 años y más:

$$
\text { a) } h(i, j, t)=\frac{H(i, j, t)}{P(i, j, t)}
$$

\section{Donde}

$h(i, j, t)$ : la tasa de jefatura específica para el sexo $i$, la edad $j$ y el momento $t$ $P(i, j, t)$ : población del sexo $i$, edad $j$ en el momento $t$

$H(i, j, t)$ : número de personas de referencia de hogar de sexo $i$, edad $j$ en el momento $t$

$$
\text { b) } \sum_{i} \quad \sum_{j} H(i, j, t+x)=\sum_{i} \quad \sum_{j} P(i, j, t+x) \times h(i, j, t+x)
$$

Donde el número total de hogares en el año $t+x$ es igual a la población proyectada para el año $t+x$ del sexo $i$ y la edad $j$ multiplicado por la tasa de jefatura específica correspondiente al mismo año, sexo y grupo de edad.

En este caso, para las proyecciones de población de base, se recurrió a las proyecciones de población por departamento realizadas por el Instituto Nacional de Estadística y Censos (INDEC), de donde se obtiene la población de 2011-2025 para un único escenario (INDEC, 2015). El horizonte 2025 de estas proyecciones determina también nuestro horizonte temporal, por lo que

7. En las fuentes argentinas es la persona reconocida como tal por los demás miembros del hogar. 
nuestra contribución es más relevante en la propuesta metodológica que en la aportación empírica. Sobre esta proyección, se aplicó una proyección de las tasas de jefatura de creación propia y con detalle territorial que se explicará a continuación. Para ello se observaron las tendencias recientes en la formación de hogar obtenidas a partir del cálculo de las tasas de jefatura correspondientes a los censos de población de 1991, 2001 y 2010.

Los datos procedentes del censo de 1991 recibieron un tratamiento especial, puesto que por entonces la RMBA se encontraba compuesta por 34 municipios, que devinieron en los actuales 40 tras reformarse en 1994 la división político-administrativa de la provincia de Buenos Aires (INDEC, 2003). Los datos de 1991 se reconstruyeron para los actuales 40 municipios mediante operaciones sobre la cartografía y la información estadística correspondiente a unidades geoestadísticas menores (radios censales) ${ }^{8}$.

\subsection{Proyecciones de población del INDEC}

La utilización de las proyecciones de población del INDEC supone traer a colación sus hipótesis y la metodología para el detalle local necesario en este trabajo.

Por lo que respecta a las hipótesis de los componentes demográficos, en el ámbito provincial, que atañe aquí a la CABA y la Provincia de Buenos Aires, el INDEC ha previsto que la esperanza de vida continuará en aumento y la fecundidad continuará en descenso. Y el saldo migratorio, que fue de 15.000 personas en el total del país en 2010, descenderá hasta ser nulo en 2040 (INDEC, 2013a y 2013b). Esto significa que a largo plazo mengua uno de los factores dinamizadores del crecimiento demográfico y, por lo tanto, del crecimiento de hogares.

Para la obtención de proyecciones departamentales (que sirven aquí para reconstruir la RMBA y distinguir los municipios que la conforman), el INDEC extrapoló con una función logística las proporciones que representan las áreas menores (departamentos) con respecto a las mayores (provincias), y luego las ajustó a los efectos de que sean consistentes con la población del área mayor proyectada (INDEC, 2015) ${ }^{9}$. El hecho (fuera de nuestro alcance) de que no se formulen hipótesis de la incidencia de las migraciones en este nivel — cuando en el último período intercensal han arrojado un leve saldo negativo en el total de la Región, pero a la vez explican la mitad del crecimiento de algunos de los municipios más dinámicos (Marcos y Chiara, 2019)— puede significar una

8. Los resultados obtenidos arrojaron diferencias con relación a datos publicados por el INDEC en la sección «Resultados» del censo de población 2001 (cuadro 2.1). Las mayores se dan en el caso de los municipios de Ezeiza (9,4\%), Esteban Echeverría (4,4\%), Presidente Perón $(3,8 \%)$ e Ituzaingó $(1,9 \%)$, mientras que en Cañuelas, Hurlingham, José C. Paz, Morón, Pilar y San Miguel son menores al $1 \%$.

9. Las proyecciones departamentales por sexo debieron desagregarse por edad en el marco de este trabajo, mediante la planilla CTBL32 (Subnational Proyections Toolkit, RUPEX: $<$ https://www.census.gov/data/software/sp-toolkit/documentation.html>), perteneciente a los programas informáticos del United States Census Bureau que utiliza el INDEC. 
Figura 1. Población censada (1991 y 2001) y proyectada (2010-2025) por grupos decenales de edad. Región Metropolitana de Buenos Aires

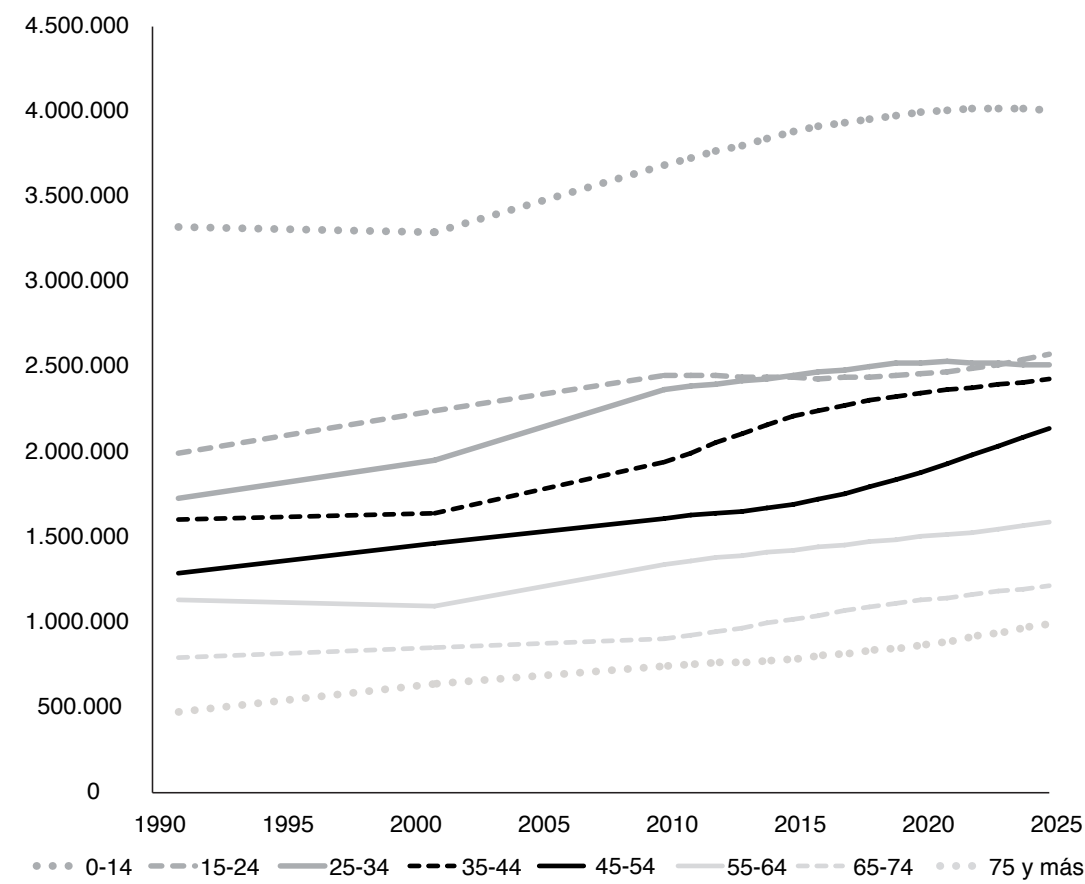

Fuente: elaboración personal basada en el INDEC, censos de 1991-2010 y proyecciones de población.

minusvaloración de la demanda efectiva de vivienda futura en esos contextos, en caso de que los flujos continúen activos.

Según las proyecciones, la población de la RMBA pasaría de 15,0 millones en 2010 a 17,4 en 2025, un aumento de 2,4 millones en 15 años. Anualmente se incorporarían 160.000 personas a la población, a una tasa media de $0,99 \%$ en descenso. Si se observa la evolución pasada y futura de la población por edad (figura 1), todos los grupos aumentan de volumen. Sin embargo, el grupo más relevante para la creación de hogares, el de 25-34 años, tendría un aumento relativamente reducido (2,4 a 2,5 millones), y con tendencia a la desaceleración. Por otro lado, la población de más de 75 años, que concentra la disolución de hogares por mortalidad, tendrá un crecimiento importante y acelerado, propio de su envejecimiento. En general, el aumento previsto de la población favorecerá que la cantidad de hogares metropolitanos continúe creciendo y con ello la demanda agregada de viviendas. Sin embargo, el equilibrio progresivo entre jóvenes adultos y personas mayores y la consecuente reducción paulatina futura de la demanda demográfica de vivienda (Módenes y López-Colás, 2014) quedan fuera de nuestro ámbito temporal. 
Figura 2. Tasa de jefatura por grupos decenales de edad. Región Metropolitana de Buenos Aires, 2010

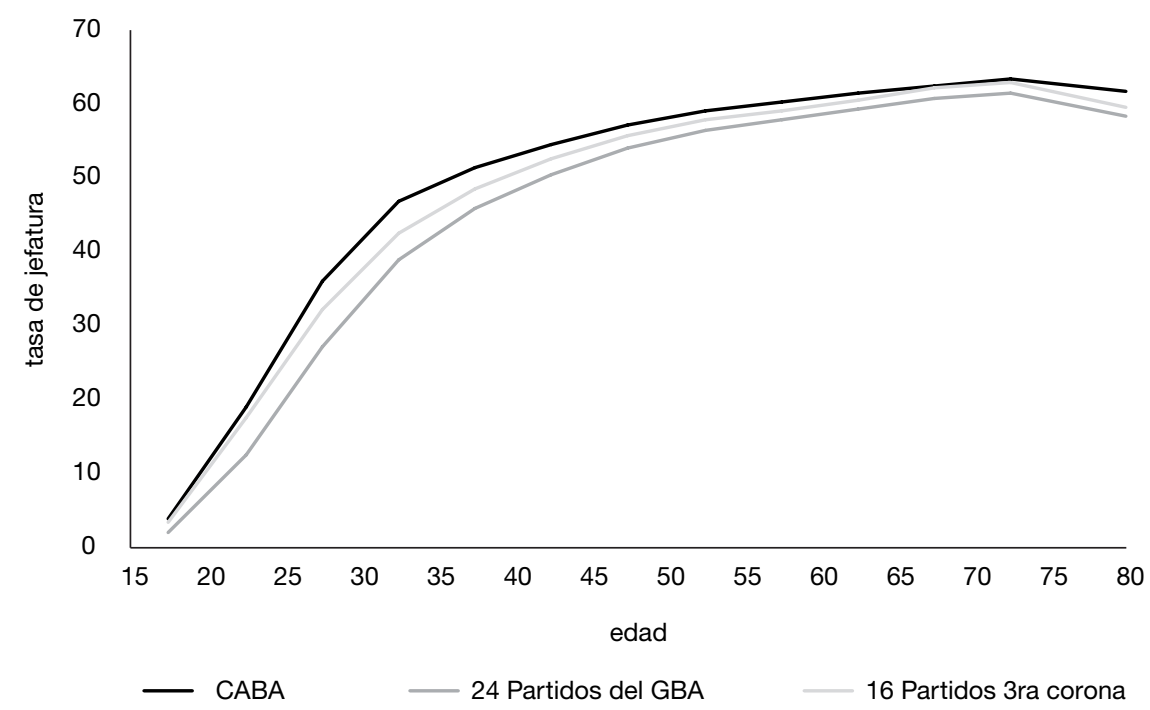

Fuente: elaboración personal basada en el INDEC, censo de 2010.

\subsection{Tendencias espaciotemporales de las tasas de jefatura}

Según datos del último censo (figura 2), las tasas de jefatura en la RMBA reproducen la forma general conocida, creciente con la edad. Siempre siguiendo ese patrón etario, la propensión a encabezar hogares es mayor en la CABA que en el resto de la Región, y la diferencia es más acentuada con respecto a los 24 partidos que la circundan y entre las personas menores de 50 años.

Entre 1991 y 2010 , la propensión a encabezar hogares solo aumentó significativamente entre los mayores de 40 años, si consideramos toda la RMBA (figura 3). En la CABA, el incremento fue casi generalizado en todas las edades, pero entre los menores de 30 años el salto positivo se produjo entre 2001 y 2010, una vez superadas las condiciones económicas desfavorables para la emancipación de la década de $1990^{10}$. En el resto de la Región, la tendencia fue similar, pero las tasas de jefatura de los más jóvenes de 2010 no alcanzaron los niveles de 1991.

Los resultados de la RMBA son coherentes con lo que se conoce sobre la formación de hogares en el conjunto de América Latina: muestran un modelo de baja formación de hogar (emancipación tardía), menos acentuado que el de otros países de la región (CEPAL-OIJ, 2004, Yépez et al., 2012a), pero alejado de la más rápida que se da en muchos países occidentales (Módenes

10. Esto puede explicar los problemas hallados por Sergio et al. (2016) al proyectar los hogares de la Provincia de Buenos Aires utilizando las tazas de jefatura observadas en 2001. 
Figura 3. Evolución de la tasa de jefatura por grupos decenales de edad

RMBA
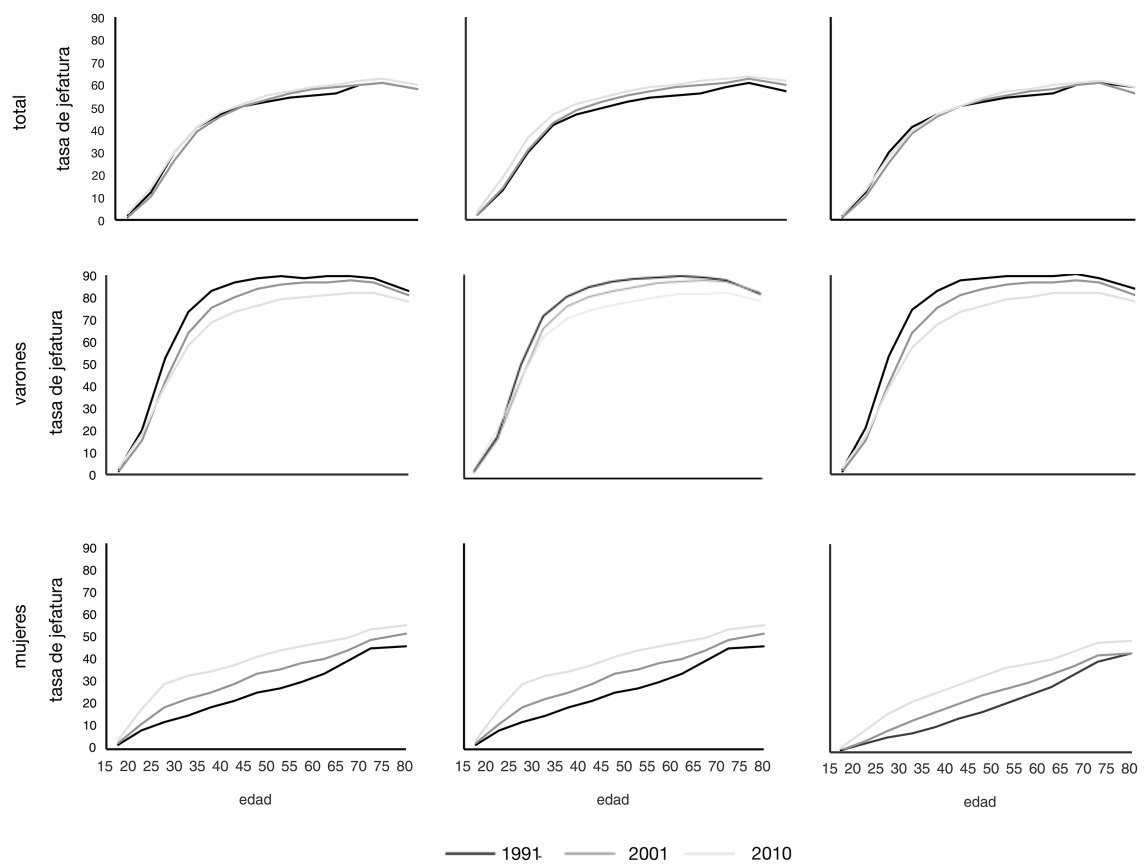

edad

Fuente: elaboración personal basada en el INDEC, censos de 1991-2010.

y López-Colás, 2014). Este modelo restrictivo es más claro en la periferia de la RMBA, donde las dificultades sociales y económicas para la transición a la adultez son mayores. Las proyecciones que se realizan aquí, aunque dinámicas, no alterarán este modelo, que implica, a su vez, una restricción del total de hogares ligados a esa población, aunque se plantearán hipótesis que modifican su patrón espacial.

Por otro lado, se observan sustanciales cambios en la propensión a encabezar hogares por sexo ligados a profundos cambios culturales (García y Rojas, 2002; Binstock, 2004), en el sentido de que las tasas de jefatura de las mujeres han aumentado en detrimento de las de los varones en la población de todas las edades y contextos geográficos.

A partir de la exploración de evolución de las tasas de jefatura, se tomaron dos decisiones relativas a su utilización para la proyección de los hogares metropolitanos:

1) Priorizar la desagregación por edad y no por sexo en los cálculos, puesto que evita, por un lado, tener que proyectar la evolución futura de un cambio en curso de tipo cultural; y, por el otro, desagregar en exceso las proyecciones departamentales, lo cual compromete la robustez de los datos. 
2) Considerar la evolución reciente (2001-2010) de las tasas para la población mayor de 35 años y la evolución de 1991-2010 de los grupos más jóvenes para neutralizar el efecto que produce la salida de la crisis de 2001. Por lo tanto, la proyección de hogares estima el incremento inercial de la cifra de hogares y deja de lado eventuales oscilaciones coyunturales cíclicas, difícilmente previsibles.

\subsection{Hipótesis de evolución de las tasas de jefatura}

Para tratar la incertidumbre acerca de la evolución futura de la proporción de población de cada grupo etario que será jefe de hogar, se proponen tres hipótesis (figura 4) que se aplican al único escenario de la proyección de población:

a) Hipótesis constante: las tasas de jefatura observadas en el último censo (2010) se mantienen invariables hasta el horizonte de 2025 y la cantidad de hogares se modifica por efecto del cambio poblacional. En comparación con las otras hipótesis, permite visualizar la contribución del componente poblacional y de la propensión a formar hogares. Funcionará como umbral mínimo de la demanda dinámica de vivienda ${ }^{11}$.

b) Hipótesis intermedia: las tasas de jefatura evolucionarán linealmente al alza, de modo que en el período 2010-2025 continúan creciendo al ritmo observado en el período 1991-2010 en el caso de la población de 15 a 34 años, y en el último período intercensal (2001-2010) en el caso de la población de 35 años y más. Se trata del panorama futuro más probable de continuar las tendencias del pasado reciente y se utilizará como insumo para el análisis espacial.

c) Hipótesis de alto crecimiento: dado por la evolución geométrica de las tasas de jefatura de la CABA y por la tendencia a la convergencia entre las tasas de la CABA y las de los municipios del resto de la Región, de modo que estos últimos alcanzarán en 2025 los niveles observados en la CABA en 2010. Es una hipótesis más optimista e improbable respecto al cambio en la formación de hogar, que supondría la eliminación de las diferencias socioeconómicas y culturales entre la CABA y su conurbación. Proporcionará como resultado un límite máximo de la demanda dinámica.

El ejercicio de previsión de la demanda demográfica de vivienda se realiza bajo el supuesto común de que no habrá cambios sustantivos en el sistema general actual de formación de hogar. No se prevé un cambio hacia un modelo de rápida formación de hogar y mayor demanda de vivienda propia de países del norte de Europa, ni un empeoramiento radical del proceso de independencia residencial de los jóvenes, retracción de la demanda y empeoramiento del déficit (que de hecho podría estar ocurriendo en la coyuntura actual).

11. En ausencia de nuevas crisis socioeconómicas graves no previsibles por definición, como la que puede acarrear la irrupción de la COVID-19. 
Figura 4. Evolución de la tasa de jefatura según censo e hipótesis. Región Metropolitana de Buenos Aires, 1991-2025

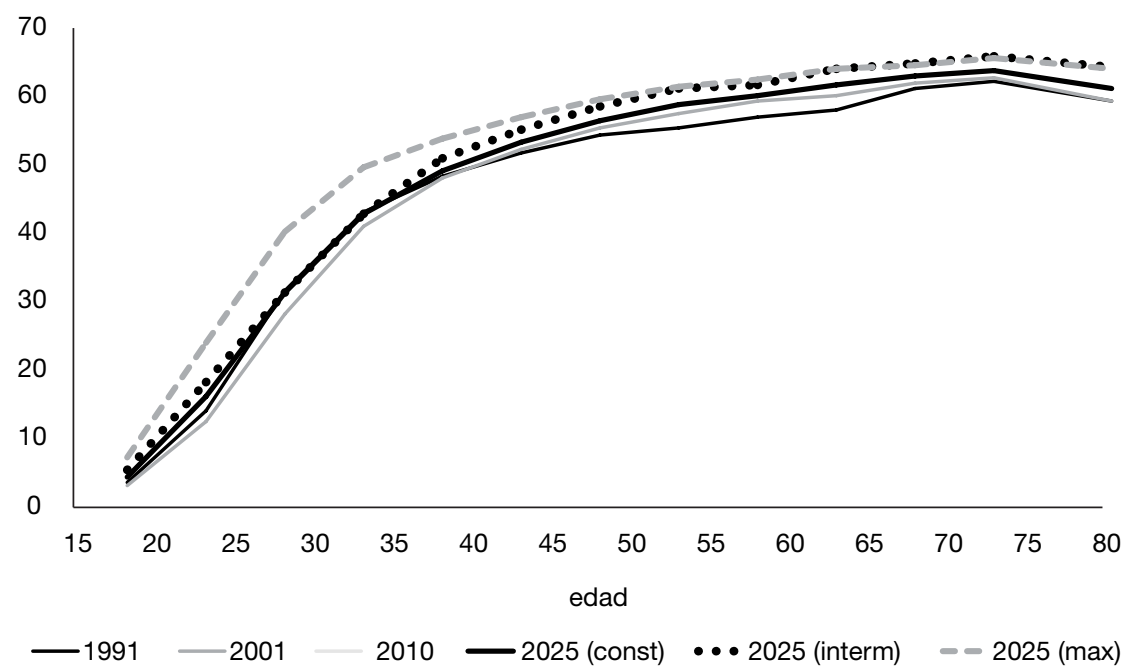

Fuente: elaboración personal basada en el INDEC, censos de 1991-2010.

\subsubsection{Estimación e interpretación de los flujos demográficos de creación $y$ desaparición de hogares}

Según Módenes y López-Colás (2014), la dinámica demográfica supone en el futuro: a) la creación de nuevos hogares, por la llegada a edades adultas de nuevas cohortes de población y por la transición de personas hacia edades en que hay mayor propensión a ser cabeza de hogar; $b$ ) la disolución de hogares por el fallecimiento de sus integrantes o por la llegada de las cohortes más antiguas a edades de vejez frágil en que las personas ya no pueden valerse por sí mismas. Desde una perspectiva longitudinal, se pueden calcular entonces flujos de creación y desaparición de hogares, interpretables como volúmenes demográficos de demanda y liberación de viviendas, y obtener por diferencia entre ambos el saldo neto de nuevas viviendas necesarias, bajo el supuesto de que las existentes que se liberen son de suficiente calidad y por lo tanto reutilizables, y que tras la desaparición de los hogares que las ocupan reingresarán inmediatamente al mercado inmobiliario para alimentar la oferta.

La figura 5 muestra cómo se han calculado flujos futuros de creación y desaparición de hogares con base a las proyecciones realizadas. Allí se observa que, según la hipótesis intermedia, las cohortes de personas de entre 15 y 34 años en 2020 alcanzarán en 2025 edades en las que la propensión a ser jefes de hogar es mayor. Ese sector del esquema (gris oscuro) se completa con la creación para 2025 de nuevos hogares por la inminente llegada a edades de demanda de los nacidos entre 2005 y 2009. 
Figura 5. Ejemplo de flujos de creación/desaparición de hogares (hipótesis intermedia). Región Metropolitana de Buenos Aires, 2020-2024

\begin{tabular}{|c|c|c|c|c|c|}
\hline \multicolumn{3}{|c|}{ hogares proyectados por edad del jefe } & \multicolumn{2}{|c|}{ flujo de hogares 2020-2024 } & \\
\hline Edad del jefe & $\begin{array}{c}01 / 07 / 2020 \\
\text { (a) }\end{array}$ & $\begin{array}{c}01 / 07 / 2025 \\
\text { (b) }\end{array}$ & $\begin{array}{l}\text { quinquenal } \\
\text { (b) - (a) }\end{array}$ & $\begin{array}{c}\text { anual } \\
{[(\mathrm{b})-(\mathrm{a})] / 5}\end{array}$ & \\
\hline $15-19$ & 38.537 & 44.778 & & & \\
\hline $20-24$ & 193.003 & 208.582 & & & \\
\hline $25-29$ & 376.071 & 368.675 & 633.799 & 126.760 & flujo de \\
\hline $30-34$ & 518.320 & 520.859 & & & entrada \\
\hline $35-39$ & 575.827 & 616.836 & & & \\
\hline $40-44$ & 613.524 & 626.397 & & & \\
\hline $45-49$ & 568.652 & 645.536 & 103.870 & 20.774 & flujo \\
\hline $50-54$ & 509.658 & 595.411 & $103.8 / 0$ & 20.174 & \\
\hline $55-59$ & 470.737 & 504.187 & & & \\
\hline $60-64$ & 440.002 & 468.429 & & & \\
\hline $65-69$ & 387.429 & 417.753 & -292948 & -58590 & \\
\hline $70-74$ & 324.933 & 355.664 & -292.948 & -58.590 & salida \\
\hline 75 y más & 533.578 & 621.885 & & & \\
\hline Total $^{\star}$ & 5.550 .271 & 5.994 .992 & 444.722 & 88.944 & saldo \\
\hline
\end{tabular}

* Excluye hogares con jefe menor de 15 años.

Fuente: elaboración personal basada en el INDEC, censos de 1991-2010 y proyecciones de población.

Las cohortes que alcanzan edades adultas intermedias en 2020 (gris intermedio), que en el esquema van de los 35 a los 54 años, también darán lugar a la creación moderada de nuevos hogares en 2025, fundamentalmente por separaciones, divorcios y situaciones de viudez.

Finalmente, entre las personas de 55 y más años en 2020 (gris claro), la expectativa es que las tasas de jefatura tiendan al descenso y que en 2025 esas cohortes, en la medida que transiten (hacia) la vejez y el final de la vida, generen un flujo de desaparición de hogares.

La compensación parcial del flujo de creación de hogares con el flujo de salida da lugar a un saldo neto quinquenal. Esto quiere decir que, en el ejemplo, a pesar de que entre 2020 y 2024 se crearán 737.669 hogares (633.799 + 103.870), las necesidades habitacionales de 292.948 de ellos podrían ser cubiertas por el reingreso al mercado inmobiliario de las viviendas que se liberen por el flujo de desaparición de hogares. De ello se deriva que la cantidad mínima de nuevas viviendas que se deberían haber construido para el final de ese quinquenio es 444.722 (88.944 por año).

La demanda por formación de hogares que puede ser satisfecha con viviendas existentes de hogares que desaparecen constituye un índice de madurez demográfica de la demanda futura de vivienda (InMaDe), que se calcula según la siguiente fórmula:

$$
\operatorname{InMaDe}=\frac{\text { Hogares disueltos }\left(\text { flujo }_{\text {salida }}\right)}{\text { Hogares formados }\left(\text { flujo }_{\text {entrada }}+\text { flujo }_{\text {intermedio }}\right)} \times 100
$$

El InMaDe se interpreta como el porcentaje de la demanda demográfica de vivienda susceptible de ser satisfecho con las viviendas que se liberen por 
la desaparición de los hogares que residen en ellas. Valores próximos a 100\% (o superiores en casos extremos) corresponden a poblaciones envejecidas con alta rotación de viviendas, en las que la inmensa mayoría de los nuevos hogares encontrarán una vivienda existente desocupada para reutilizar; y, en el extremo opuesto, valores próximos a $0 \%$ corresponden a poblaciones jóvenes con escasa rotación de viviendas, en las que la demanda neta final se acerca a la creación de hogares, la cual debe ser satisfecha básicamente por construcción de vivienda nueva.

Sin embargo, el InMaDe constituye el umbral inferior de un intervalo de demanda futura demográfica de viviendas, que puede verse elevado por distintos motivos hasta alcanzar (en situaciones extremas) el umbral superior definido por la totalidad de los hogares que se crean (flujo de entrada + flujo intermedio). En el ejemplo, la necesidad anual de construcción de nuevas viviendas va de un mínimo de 88.944 a un máximo de $147.534(126.760$ + 20.774).

Esta identificación de un intervalo de demanda futura demográfica de viviendas, más que una única cifra, es imprescindible, puesto que hay procesos que provocan que las nuevas viviendas a construir superen el saldo neto de hogares: 1) el agotamiento de la vida útil de las viviendas existentes (la mortalidad de las viviendas); 2) que en las viviendas de los hogares que desaparecen haya más de un hogar y tras la desaparición de uno de ellos la vivienda no quede desocupada; y 3) que las viviendas que se liberen por desaparición de hogares no sean de buena calidad y por lo tanto habitables por otros hogares; o 4) que estén destinadas por los herederos a uso no residencial o reserva de valor desocupada (las llamadas viviendas ociosas). Las situaciones 2) y 3 ) tienen que ver con la existencia o no de problemas de déficit habitacional cualitativo (calidad de las viviendas) y cuantitativo (hogares que no residen en viviendas independientes). Ello permite igualmente la integración final de las dos grandes dimensiones de las necesidades de vivienda: las necesidades sociales presentes y las necesidades demográficas de futuro.

En el contexto latinoamericano, donde el stock existente presenta graves problemas de calidad, es particularmente necesario proponer intervalos, y en la escala local el análisis debe ser completado con una evaluación de la calidad del parque existente, que aquí se propone integrar en los llamados escenarios de planificación.

\subsection{Proyección de hogares a escala municipal y escenarios de planificación}

Los hogares proyectados en el ámbito municipal y en el total de la RMBA deben ser consistentes entre sí. Es decir, que la sumatoria de los hogares proyectados en el ámbito municipal debe ser igual a la cantidad de hogares proyectada para el total de la RMBA. A efectos de que los resultados cumplan con este requisito, se procede de acuerdo con las siguientes etapas:

1) Se realiza la proyección de hogares del total de la RMBA.

2) Se realiza la proyección de hogares de cada uno de los municipios de la RMBA. 
3) Se suman y calculan proporciones según los resultados de la etapa 2, y se aplican a los resultados obtenidos en la etapa 1 para obtener los valores de nivel municipal ajustados.

Los municipios metropolitanos finalmente se agrupan en escenarios de planificación según los desafíos específicos para las políticas de vivienda que imperan en ellos, de acuerdo con la dinámica demográfica de creación y disolución de hogares y el pasivo habitacional del que parten.

Para ello se realiza un análisis de clúster jerárquico en el que se incluyen:

- Un indicador de intensidad potencial de la rotación demográfica de viviendas entre los hogares según la hipótesis intermedia: el InMaDe.

- Dos indicadores de la calidad del parque habitacional existente a inicios del período (2010): el porcentaje de viviendas deficitarias recuperables y el porcentaje de viviendas deficitarias irrecuperables ${ }^{12}$.

\section{Aplicación al caso de la Región Metropolitana de Buenos Aires}

Según la hipótesis constante, los hogares de la RMBA se incrementarían el 23\% entre 2010 y 2025, al pasar de 4,70 a 5,78 millones (figura 6). De acuerdo con la hipótesis intermedia, el incremento sería del $27 \%$ y la cantidad de hogares en 2025 se aproximaría a los 6 millones. Y bajo la hipótesis alta, la cantidad

Figura 6. Hogares censados y proyectados según hipótesis de evolución de las tasas de jefatura. Región Metropolitana de Buenos Aires, 1991-2025

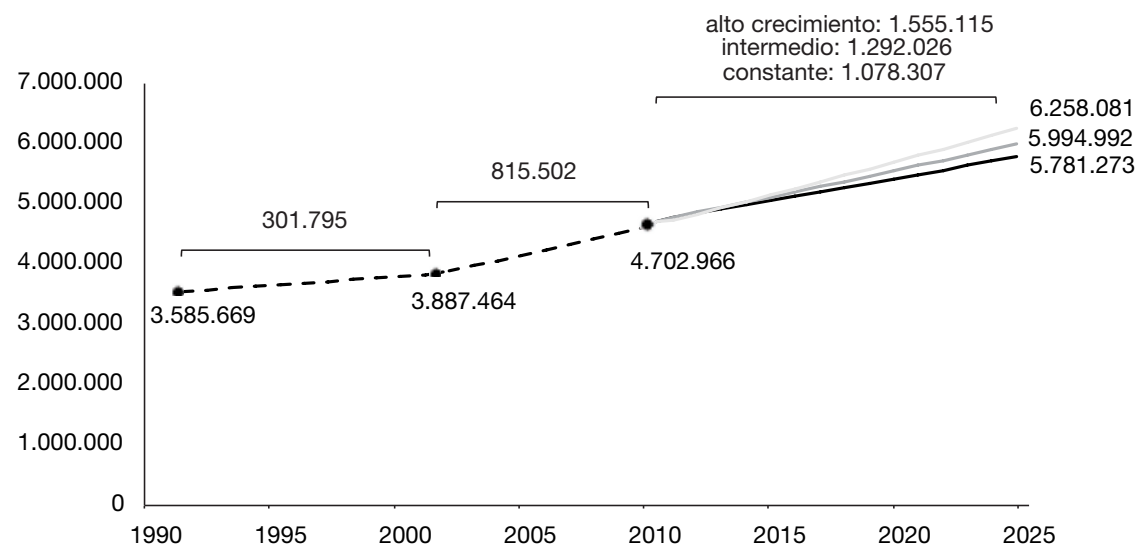

— Esc. constante — Esc. interm. Esc. alto crec. - - Interpolados - Censados

Fuente: elaboración personal basada en el INDEC, censos de 1991-2010 y proyecciones de población.

12. El indicador considera la calidad material de la vivienda (pisos y techos) y el tipo de vivienda, según Marcos et al., 2018 
Figura 7. Crecimiento de la cantidad de hogares y saldo neto proyectados por quinquenio según hipótesis de evolución de las tasas de jefatura. Región Metropolitana de Buenos Aires, 2010-2025

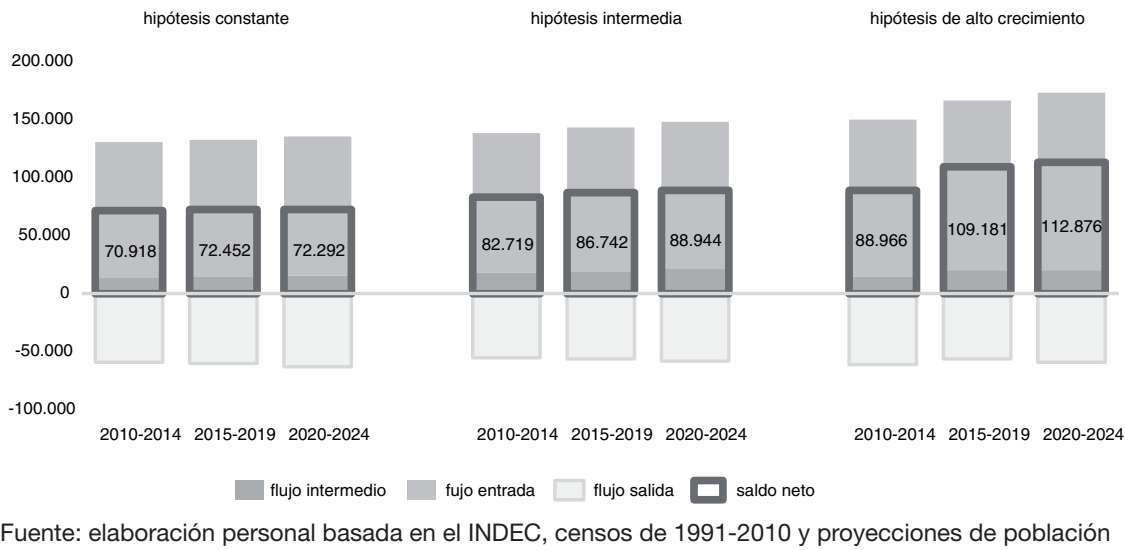

de hogares alcanzaría los 6,26 millones, un crecimiento del 33\% en 15 años. Entre 2010 y 2025 , se agregarían a la Región entre 1 y 1,5 millones de hogares, con una cifra próxima a 1,3 millones como la más probable.

La cantidad anual mínima de viviendas a construir en el quinquenio 20202024 varía sensiblemente según la hipótesis de evolución de las tasas de jefatura (figura 7). Según la hipótesis constante, la más conservadora, tan solo el crecimiento de la población y el cambio de su estructura etaria producen la necesidad de algo más de 72.000 viviendas nuevas al año. En la hipótesis intermedia, al considerarse también la continuidad del aumento de las tasas de jefatura, la cantidad mínima de viviendas a construir asciende a 89.000, y en la de alto crecimiento, que supone un aumento máximo de las tasas de jefatura, el saldo neto anual de viviendas llegaría a 113.000. Estos valores confirman la sensibilidad de las necesidades futuras a variaciones relativamente leves de la intensidad y el calendario de la formación de hogares. En el caso de la hipótesis intermedia, el $21 \%$ de las nuevas viviendas demandadas en el quinquenio 2020-2024 se explicaría por la ligera continuidad alcista de las tasas de jefatura (17.000 de las 89.000 nuevas viviendas necesarias al año de la hipótesis intermedia se deben a ese cambio).

Es importante recordar que el saldo neto anual de nuevos hogares es un valor mínimo de las nuevas viviendas requeridas. De acuerdo con la hipótesis intermedia (con la que se trabaja de forma exclusiva a partir de ahora), la cantidad anual mínima de nuevas viviendas a construir para cubrir las necesidades habitacionales de los hogares que se creen entre 2020 y 2024 es de 88.994 (saldo neto), pero ese mínimo necesario siempre será superior y puede llegar hasta 147.534 (flujo creación más flujo intermedio) en la situación extrema de que ninguna de las viviendas de los 58.590 hogares que desaparecerían reingresara al mercado. Es decir, la demanda demográfica inicial de formación de hogares (147.000) puede ser como máximo satisfecha en un 39,7\% por viviendas ya existentes (InMaDe bajo). 
Figura 8. Escenarios de planificación según calidad del parque habitacional y perspectivas demográficas de rotación de viviendas (InMaDe). Región Metropolitana de Buenos Aires, 2010
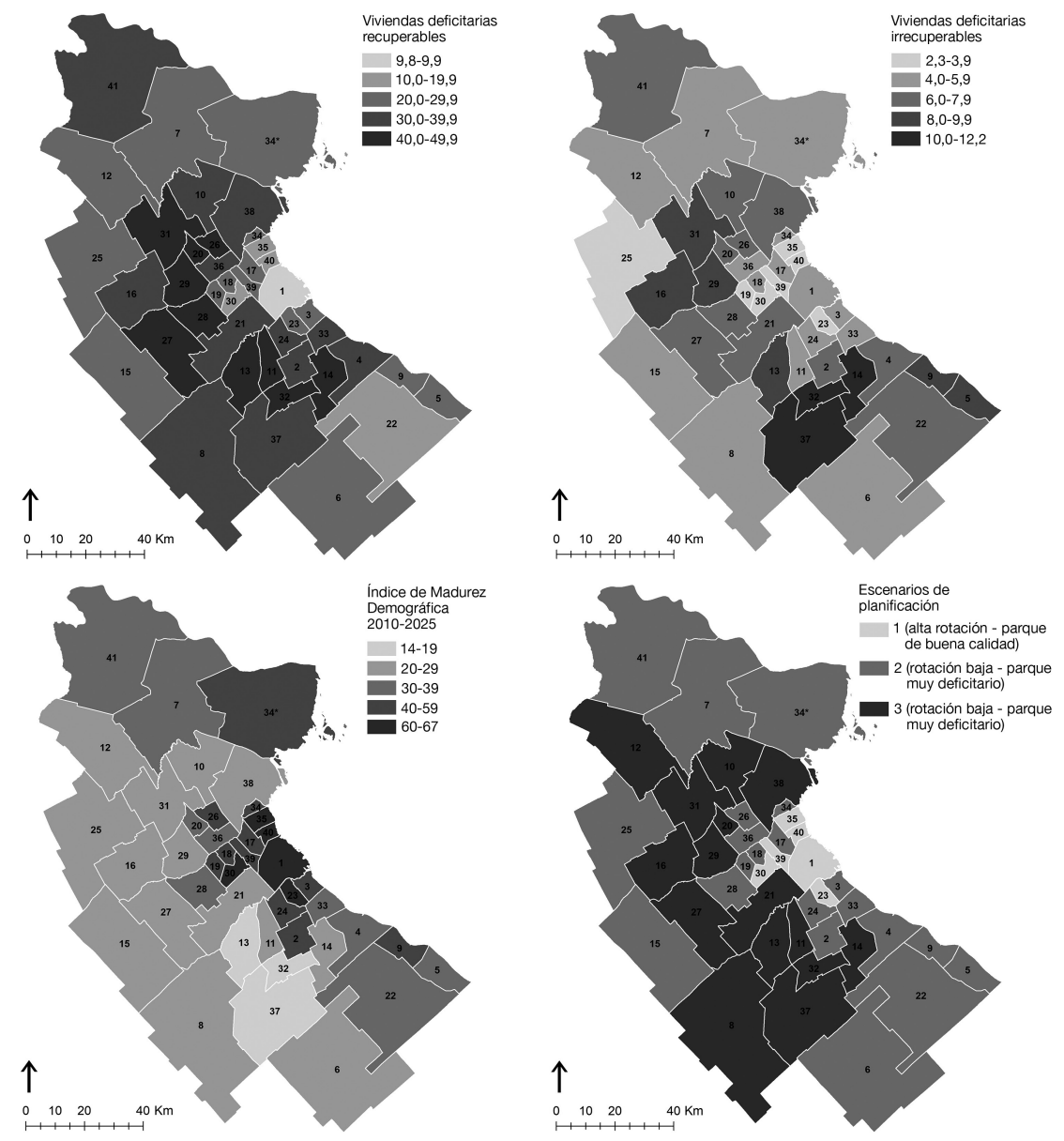

\section{Municipio}

1 C. Aut. de Buenos Aires 11 Esteban Echeverría

2 Almirante Brown 12 Exaltación de la Cruz

3 Avellaneda

4 Berazategui

13 Ezeiza

14 Florencio Varela

5 Berisso

6 Brandsen

7 Campana

15 Gral. Las Heras

16 Gral. Rodríguez

17 Gral. San Martín

8 Cañuelas

18 Hurlingham

9 Ensenada

19 Ituzaingó

10 Escobar

20 José C. Paz

21 La Matanza
22 La Plata
23 Lanús
24 Lomas de Zamora
25 Luján
26 Malvinas Argentinas
27 Marcos Paz
28 Merlo
29 Moreno
30 Morón
31 Pilar

32 Pte. Perón

33 Quilmes

34 San Fernando

34 *Islas de San Fernando

35 San Isidro

36 San Miguel

37 San Vicente

38 Tigre e Islas

39 Tres de Febrero

40 Vicente López

41 Zarate

Fuente: elaboración personal basada en el INDEC, censos de 1991-2010 y proyecciones de población. 
En el interior de la RMBA ${ }^{13}$ se identificaron tres escenarios de planificación (figura 8), definidos por la calidad del parque habitacional existente a inicios del período y la relevancia que tendrán sus viviendas ya existentes para cubrir las necesidades habitacionales futuras $\left.{ }^{14}: 1\right)$ escenario de alta rotación de las viviendas y parque habitacional de calidad; 2) escenario de moderada rotación de las viviendas y parque habitacional de mediana calidad; y 3) escenario de baja rotación de las viviendas y parque habitacional muy deficitario. Este resultado indica una correlación espacial positiva entre rotación y madurez demográfica y calidad del parque en el caso de Buenos Aires.

En el escenario de alta rotación de las viviendas y parque habitacional de calidad, conformado por la CABA y otros cinco municipios próximos a ella, el InMaDe es bastante alto (alrededor del 60\%) (figuras 9 y 10). Esta característica se explica por el mayor envejecimiento de este núcleo de municipios, que se traduce en flujos de desaparición de hogares proporcionalmente mayores y, por lo tanto, saldos netos de demanda de nuevas viviendas más condicionados por la calidad de las viviendas que se desocupen y el destino que se les den.

La buena calidad del parque habitacional de este grupo de municipios favorece la dinámica de rotación de las viviendas, porque la mayoría de las que se vayan liberando son habitables, excepto aquellas muy antiguas que deban sustituirse. Sin embargo, al mismo tiempo en estos municipios el mercado inmobiliario impone mayores obstáculos a la dinámica de rotación de viviendas: gran demanda de localizaciones privilegiadas, los mayores precios de alquiler y venta, y uso no residencial de las viviendas (reserva de valor, alquiler turístico, destino comercial, etcétera) (Baer, 2012; Baer y Kauw, 2016). La CABA es así el epicentro de un escenario de planificación en el que debiera prestarse especial atención a facilitar la rotación de las viviendas liberadas entre sucesivos hogares, así como su asequibilidad en condiciones de tenencia formal y segura para los nuevos hogares que las ocupen. Hay que observar, finalmente, que, si bien el déficit habitacional es reducido, puede ser de más difícil gestión —en particular cuando su severidad requiere reemplazar las viviendas-, dado el escaso suelo vacante en estos municipios y la complejidad de hacer reemplazos in situ y hasta reurbanizaciones de barrios completos $^{15}$.

13. Los datos correspondientes a cada municipio pueden consultarse en Marcos y Módenes (2019).

14. Hubiera sido sumamente enriquecedor incorporar datos acerca de la construcción de viviendas al análisis en general y, en particular, como variable interviniente en la delimitación de escenarios de planificación. Sin embargo, en Argentina las estadísticas sobre el tema son incipientes, heterogéneas y no abarcan el fenómeno de la construcción de nuevas viviendas en su totalidad (existen más datos de la CABA que de la Provincia de Buenos Aires, donde se conocen solo los metros de uso residencial permitidos para la construcción, y esas estadísticas excluyen las construcciones y ampliaciones informales).

15. Véase al respecto el informe del CESBA (2017) acerca de los procesos de reurbanización e integración socio-urbana en la CABA. 
Figura 9. Crecimiento anual de la cantidad de hogares y saldo neto proyectados según escenario de planificación. Región Metropolitana de Buenos Aires, 2010-2025

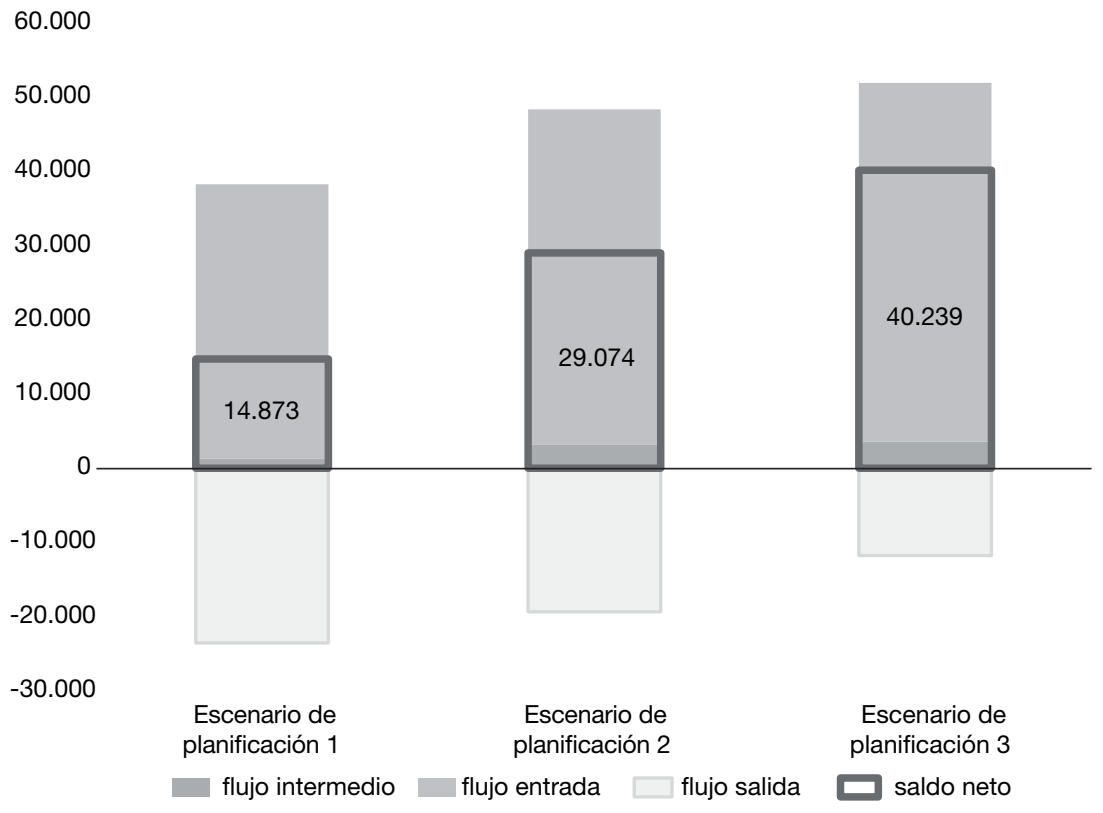

Fuente: elaboración personal basada en el INDEC, censos de 1991-2010 y proyecciones de población.

El escenario de moderada rotación de las viviendas y parque habitacional de mediana calidad está constituido por una veintena de municipios: un grupo de ellos completa la primera corona de partidos metropolitanos, colindantes o próximos a la CABA, y un segundo grupo está compuesto por la mayoría de los partidos de la tercera corona, que tienen por cabecera ciudades físicamente independientes de la aglomeración Gran Buenos Aires. La dinámica de rotación futura de las viviendas es más moderada que en el primer escenario (InMaDe en torno al 40\%), pero ello es compensado por mayores problemas de calidad constructiva del parque habitacional existente, que afectan al $35 \%$ de las viviendas (el 29\% requiere mejoras en su materialidad y el 5,7\% de ellas deben ser reemplazadas dado que son irrecuperables). Es decir, que se trata de un escenario de planificación que presenta desafíos tanto para garantizar la rotación del parque existente como para construir la vivienda nueva faltante.

El último escenario de planificación se define por la baja rotación de las viviendas y el parque habitacional muy deficitario, y corresponde, aproximadamente, a la segunda corona de municipios. Es decir, que se trata de los últimos municipios alcanzados por el crecimiento de la aglomeración Gran Buenos Aires y peor integrados a ella en términos de conectividad, servicios y condiciones de vida en general, lo cual incluye la calidad constructiva de las viviendas, que es deficitaria en casi la mitad de los casos. El poblamiento más 
Figura 10. Escenarios de planificación y políticas prioritarias según calidad del parque habitacional y perspectivas demográficas de rotación de viviendas (síntesis). Región Metropolitana de Buenos Aires, 2010
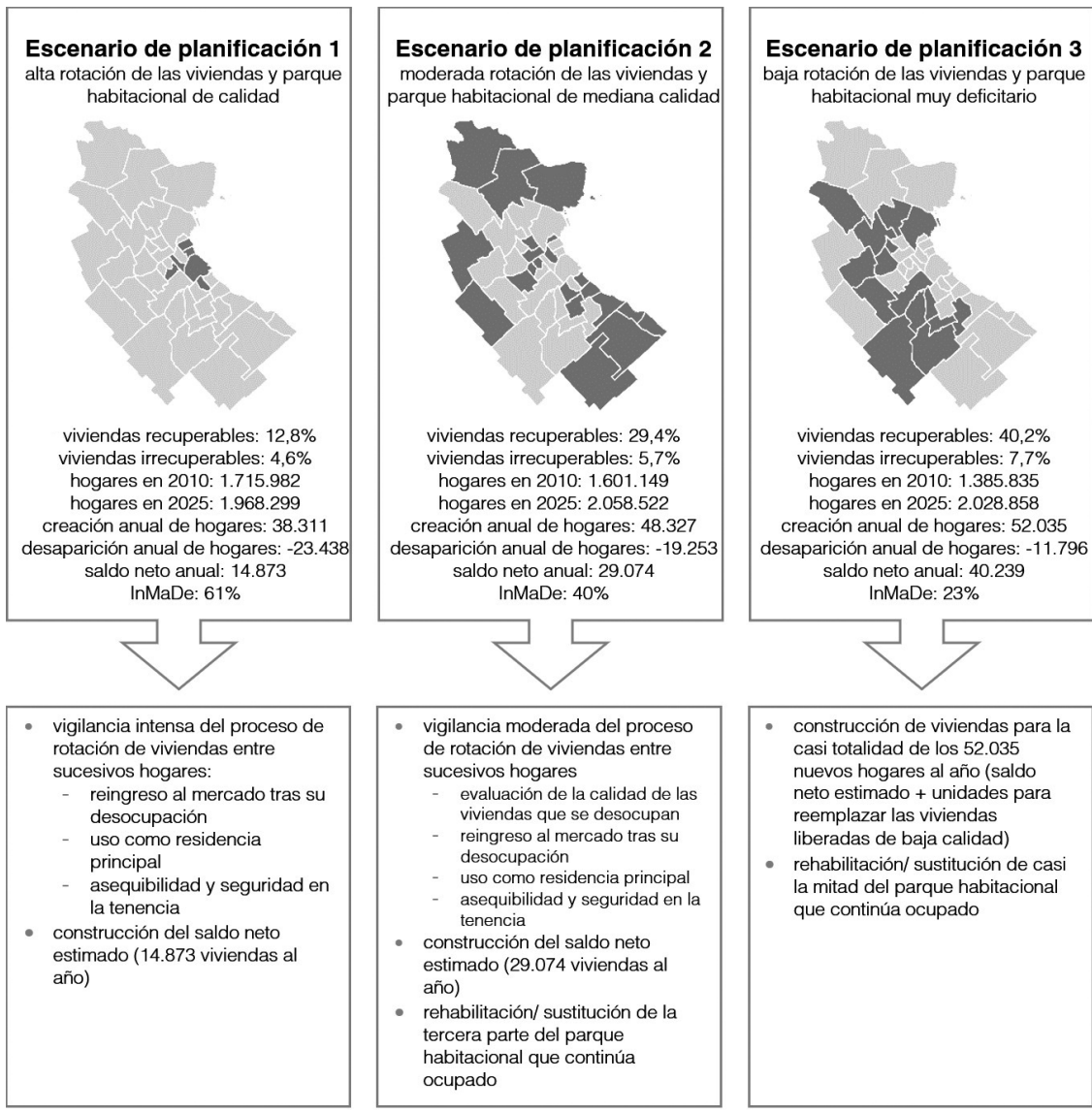

Fuente: elaboración personal.

tardío del área y la dinámica demográfica más acelerada de la población de menor nivel socioeconómico redundan en una estructura etaria relativamente joven y bajos niveles proyectados de desaparición de hogares de ancianos. El impacto en la liberación de viviendas podría ser, a su vez, menor por la corresidencia de hogares en las viviendas.

En este tipo de municipios, las políticas habitacionales estarán mucho más exigidas. Por un lado, la demanda demográfica de nuevos hogares deberá ser satisfecha básicamente por construcción de nuevas viviendas accesibles (el InMaDe suele ser inferior al 30\%). Y además no se debe olvidar la necesidad de rehabilitar el $40 \%$ del parque habitacional que presenta deficiencias constructivas y de reemplazar el casi $8 \%$ del parque existente, cuya materialidad es 
irrecuperable. En este contexto, la disponibilidad de tierra vacante constituye una ventaja, pero emergen como elementos de planificación clave las regulaciones tendentes a movilizar el suelo y los grandes esfuerzos públicos requeridos para financiar la extensión de las redes de servicios y la construcción de las viviendas destinadas a buena parte de la demanda demográfica futura (dado que muchos hogares no podrán acceder a la oferta del mercado) y a reemplazar las de muy mala calidad.

\section{Reflexiones finales}

La preocupación que guía este trabajo - la cuestión de la vivienda en contextos urbanos de crecimiento poblacional y déficit habitacional- constituye un tema central tanto como objeto de conocimiento científico como en materia de políticas públicas. La vivienda es un componente básico para la calidad de vida de las personas, proveedora de abrigo y entorno vital fundamental para el desarrollo individual y familiar. Sin embargo, persisten importantes lagunas en el conocimiento sobre el tema en América Latina, en especial en lo relativo a la posibilidad de anticipar las necesidades habitacionales.

La producción de conocimiento sobre esta problemática en la región ha alimentado fundamentalmente lo que puede considerarse un enfoque reactivo sumamente valioso, de identificación de las cuentas pendientes en materia de provisión de servicios e infraestructura, regularización dominial, requerimientos de ampliación o mejoramiento de las viviendas existentes y construcción de viviendas nuevas, ya sea para reemplazar las de calidad irrecuperable como para dotar de vivienda a hogares que no han podido acceder a una.

Los resultados obtenidos aquí contribuyen a completar ese panorama y brindan elementos metodológicos y analíticos para pensar la problemática en grandes ciudades en clave prospectiva, lo cual constituye la aportación principal de este trabajo. La proyección del crecimiento demográfico de la cantidad de hogares permite anticipar en buena medida las necesidades residenciales. Y la estimación de futuros flujos de creación y disolución de hogares - $\mathrm{O}$ condiciones demográficas para la rotación de viviendas que se derivan de la madurez de la población - constituye un elemento de contextualización local imprescindible para la planificación de necesidades. Pero la consideración de las condiciones locales de calidad del parque existente y de la dinámica del mercado inmobiliario son elementos adicionales necesarios para entender el tipo de políticas de gestión y planificación residencial que serán requeridas.

En el caso de la RMBA, el calendario de la producción de información estadística ${ }^{16}$ trazó un horizonte temporal próximo, situado en el año 2025.

16. En el momento de la escritura de este artículo, el último censo de población argentino disponible es el del año 2010, sobre el que el INDEC realizó estimaciones de población departamentales con horizonte a 2025. La realización de un nuevo censo estaba prevista para 2020 y necesariamente se pospondrá debido a la pandemia de COVID-19. Con posterioridad a ese nuevo censo, se realizarán nuevas proyecciones para replicar este trabajo con un horizonte temporal más alejado. 
Ello constituye una limitación para la aportación empírica de este trabajo, pero permitió mostrar cómo la demanda demográfica de vivienda adquiere especificidades locales que se traducen en escenarios de planificación distintos. En un extremo, el conformado por los municipios centrales — con especial protagonismo de la CABA y puntos de contacto con dinámicas y estructuras de ciudades de países desarrollados-, en el que buena parte de las necesidades habitacionales de los hogares que se crean pueden ser compensadas por las viviendas que se liberen ( $\mathrm{y}$ donde es importante vigilar la calidad del parque habitacional existente y su traspaso a las nuevas generaciones). En el otro, el correspondiente a la corona de municipios exteriores de la Región, donde el flujo de disolución de hogares es pequeño y la satisfacción de las necesidades habitacionales futuras pasa, fundamentalmente, por la construcción de vivienda nueva (de modo que la atención deberá estar puesta en su localización y asequibilidad).

El saldo neto de nuevas viviendas a construir es un dato tan importante como sensible a factores demográficos y extrademográficos que es preciso considerar si se pretende actuar en consecuencia y procurar que se garantice el derecho básico de la población a contar con una vivienda de calidad. En materia demográfica, la cantidad real de viviendas a construir puede verse afectada por el hecho de que la población, su estructura por edad, su propensión a conformar hogares y el tipo de hogares que conforma no evolucionen tal como se ha previsto.

Cuestiones extrademográficas, como la antigüedad y la calidad del parque habitacional, la existencia de más de un hogar en las viviendas de las unidades domésticas que se disuelvan, los deseos de emancipación de los hogares y núcleos familiares allegados y la dinámica que adquiera la rotación de las viviendas que efectivamente se liberen por la disolución de los hogares que las ocupan, constituyen factores que pueden significar la necesidad de construir una mayor cantidad de viviendas que la estimada (de mínima) aquí.

Este trabajo abre una línea analítica en la que será importante continuar avanzando a través del abordaje de la interseccionalidad entre los determinantes demográficos y sociales de las necesidades habitacionales. Para ello será fundamental incorporar al análisis elementos como la demanda demográfica de vivienda oculta en la corresidencia de hogares y el allegamiento interno de núcleos familiares secundarios, la proyección de los arreglos residenciales y la estimación de en qué medida los nuevos hogares tendrán medios para acceder a la oferta habitacional del mercado, para así ganar precisión y comenzar a cualificar las necesidades residenciales futuras en términos de características de las unidades de vivienda a construir y actores protagonistas de ese proceso.

\section{Referencias bibliográficas}

Aparicio, Cimar Alejandro Prieto y Lima Brusse, Gustavo Pedroso de (2018). «Demanda demográfica de viviendas: proyección de los arreglos residenciales hasta 2030 a partir de la población destinataria de un programa de vivienda social de 
la Compañía de Desarrollo Habitacional y Urbano (CDHU) en el estado de São Paulo». Notas de Población, 107, 103-129.

Arriagada, Camilo (2005). El déficit habitacional en Brasil y México y sus dos megaciudades globales: estudio con los censos de 1990 y 2000. Santiago de Chile: Centro Latinoamericano y Caribeño de Demografía (Celade). Disponible en <https:// www.cepal.org/es/publicaciones/7199-deficit-habitacional-brasil-mexico-susmegaciudades-globales-estudio-censos-1990>.

BAER, Luis (2012). «Mercados de suelo y producción de vivienda en Buenos Aires y su área metropolitana: tendencias recientes de desarrollo urbano y acceso a la ciudad». Revista Iberoamericana de Urbanismo, 8, 43-58. Disponible en <http:// hdl.handle.net/2099/13033>.

BAER, Luis; Di FilipPo, Facundo y Granero, Guadalupe (2018). «El círculo virtuoso del extractivismo urbano». Panamá Revista. Disponible en <http://www.panamarevista.com/el-circulo-virtuoso-del-extractivismo-urbano/>.

BAER, Luis y KAUW, Mark (2016). "Mercado inmobiliario y acceso a la vivienda formal en la Ciudad de Buenos Aires, y su contexto metropolitano, entre 2003 y 2013». EURE (Santiago), 42 (126), 5-25. <https://doi.org/10.4067/S0250-71612016000200001>

BelsKY, Eric S. (2009). "Demographics, Markets, and the Future of Housing Demand». Journal of Housing Research, 18 (2), 99-119. Disponible en <https:// www.jstor.org/stable/24861474>.

Binstock, Georgina P. (2004). «Cambios en las pautas de formación y disolución de la familia entre las mujeres de la Ciudad de Buenos Aires». Población de Buenos Aires, 1, 8-15.

Bramley, Glen; Pawson, Hal; White, Michael; Watkins, David y Pleace, Nicholas (2010). «Estimating housing need». Londres: Communities and Local Government.

Celade (1996). Déficit habitacional y datos censales: una metodología. Serie B 114. Santiago: CEPAL. Disponible en <https://repositorio.cepal.org/handle/11362/9781>.

CEPAL (1996). Alojar el desarrollo: una tarea para los asentamientos humanos. Santiago: CEPAL. Disponible en <https://repositorio.cepal.org//handle/11362/19425>.

CEPAL-OIJ (2004). La juventud en Iberoamérica. Tendencias y urgencias. Santiago: CEPAL.

CESBA (ed.) (2017). Acerca de la integración urbanistica y social en villas de la Ciudad de Buenos Aires. Buenos Aires: CESBA, Consejo Económico y Social de la Ciudad de Buenos Aires. Disponible en <http://bdigital.cesba.gob.ar/bitstream/ handle/123456789/412/274\%20-\%20Integracion\%20Socio\%20Urbana. pdf? sequence $=1$ \&isAllowed $=\mathrm{y}>$.

Chombart de Lauwe, P.-H. (1976). Hombres y ciudades. Barcelona: Labor.

Di Virgilio, M. Mercedes y RodríGueZ, M. Carla (2018). «Hábitat, vivienda y marginalidad residencial». En: PiOvani, Juan I. y Salvia, Agustín (eds.). La Argentina en el siglo XXI. Cómo somos, vivimos y convivimos en una sociedad desigual: Encuesta Nacional sobre la Estructura Social. Buenos Aires: Siglo XXI.

GARCÍA, Brígida y ROJAS, Olga Lorena (2002). «Los hogares latinoamericanos durante la segunda mitad del siglo Xx: una perspectiva sociodemográfica». Estudios Demográficos y Urbanos, 17 (2), 261-288. <https://doi.org/10.24201/edu.v17i2.1139>

GilberT, Alan (2000). «Housing in Third World Cities: The Critical Issues». Geography, 85 (2), 145-155. Disponible en <https://www.jstor.org/stable/40573408>. 
Givisiez, Gustavo Henrique Naves y Oliveira, Elzira Lúcia de (2005). «Projection of demographic demand for households: Application of a headship rate method based on age-period-cohort model». En: XXV International Population Conference of the IUSSP. Tours, Francia, 2005. Disponible en <http://www.demoscope.ru/ weekly/knigi/tours_2005/papers/iussp2005s52238.pdf>.

GoreliK, Adrián (2009). «Buenos Aires: el fin de la expansión». En: Pirez, Pedro. Buenos Aires, la formación del presente. Quito: Organización Latinoamericana y del Caribe de Centros Históricos (OLACCHI).

Hugo, Graeme (2005). "Implications of Demographic Change for Future Housing Demand in Australia». Australian Planner, 42 (2), 33-41. $<$ https://doi.org/10.1080/07293682.2005.9982416>

INDEC (1991). Censo Nacional de Población y Vivienda 1991. Buenos Aires: INDEC.

- (1999). «Municipio, localidad y departamento: tres conceptos que suelen confundirse». Municipium, 3.

- (2001). Censo Nacional de Población, Hogares y Viviendas 2001. Buenos Aires: INDEC.

- (2003). ¿Qué es el Gran Buenos Aires? Buenos Aires: INDEC.

- (2010). Censo Nacional de Población, Hogares y Viviendas 2010. Buenos Aires: INDEC.

- (2013a). Estimaciones y proyecciones de población 2010-2040: total del país. Buenos Aires: INDEC.

- (2013b). Proyecciones provinciales de población por sexo y grupo de edad 2010-2014. Buenos Aires: INDEC.

- (2015). Estimaciones de población por sexo, departamento y año calendario 20102025. Buenos Aires: INDEC.

KING, Peter (2009). Understanding Housing Finance: Meeting Needs and Making Choices. $2^{\text {a }}$ ed. Londres, Nueva York: Routledge.

Leal Maldonado, J. y Cortés Alcalá, L. (1995). La dimensión de la ciudad. Madrid: Centro de Investigaciones Sociológicas.

Londoño, Enrique Peñalosa (2017). Necesidades de vivienda y mercado inmobiliario en Bogotá y La Sabana 2006-2030. Bogotá Ciudades Estadísticas, 94. Bogotá: Alcaldía Mayor de Bogotá.

MACEDO, Joseli (2010). «Methodology Adaptation across Levels of Development: Applying a US Regional Housing Model to Brazil». Housing Studies, 25 (5), 607-624. <https://doi.org/10.1080/02673037.2010.483582>

Macedo, Joseli; NGuyen, Diep; O’Dell, William J. y Smith, Marc T. (2005). «Affordable housing needs assessment methodology: the adaptation of the Florida model to Brazil». World Bank's 2005 Urban Research Symposium.

Marcos, Mariana; Di Virgilio, M. Mercedes y Mera, Gabriela (2018). «El déficit habitacional en Argentina: una propuesta de medición para establecer magnitudes, tipos y áreas prioritarias de intervención intra-urbana». Revista Latinoamericana de Metodología de las Ciencias Sociales, 8. Disponible en <http://www.memoria.fahce. unlp.edu.ar/art_revistas/pr.9427/pr.9427.pdf>.

Marcos, Mariana y Chiara, Camila (2019). «El crecimiento de la población de la Región Metropolitana de Buenos Aires (2001-2010)». Revista Latinoamericana de Población, 13 (24), 106-134. <https://doi.org/10.31406/relap2019.v13.i1.n24.5>

Marcos, Mariana y Módenes, Juan Antonio (2019). Proyecciones de hogares y demanda de vivienda en la Región Metropolitana de Buenos Aires». Papers de 
Demografia, 464, Barcelona: Centre d'Estudis Demogràfics. Disponible en $<$ https://ddd.uab.cat/pub/worpap/2019/220204/PD_464.pdf>.

MATTOS, Carlos A. de (1998). "Reestructuración, crecimiento y expansión metropolitana en las economías emergentes latinoamericanas». Economía, Sociedad y Territorio, 1 (4), 723-753.

MCCuE, Daniel (2018). «Updated Household Growth Projections: 2018-2028 and 20282038». Cambridge [Mass.], Joint Center for Urban Studies, Harvard University.

Ministerio de Planificación Federal, Inversión Pública y Servicios (2015). Atlas ID. Indicadores de desarrollo territorial de la República Argentina. Buenos Aires: Subsecretaría de Planificación Territorial de la Inversión Pública. Ministerio de Planificación Federal, Inversión Pública y Servicios.

MÓDENES, Juan Antonio y LÓPEZ-COLÁS, Julián (2014). «Cambio demográfico reciente y vivienda en España: ¿hacia un nuevo sistema residencial?». Revista Española de Investigaciones Sociológicas, 148, 103-134.

Murdoch, Jonathan (2000). "Space Against Time: Competing Rationalities in Planning for Housing». Transactions of the Institute of British Geographers, 25 (4), 503-519. <https://doi.org/10.1111/j.0020-2754.2000.00503.x>

Myers, Dowell; PITKIn, John y PARK, Julie (2002). "Estimation of Housing Needs amid Population Growth and Change». Housing Policy Debate, 13 (3), 567-596. <https://doi.org/10.1080/10511482.2002.9521455>

PITKIN, John R. y MYERS, Dowell (1994). «The specification of demographic effects on housing demand: avoiding the age-cohort fallacy». Journal of Housing Economics, 3 (3), 240-250.

RATINOFF, Luis (1979). «Población y vivienda en América Latina: perspectiva de la próxima década». En: URQuidi, Víctor L. y Morelos, José B. (eds.). Población y desarrollo en América Latina. México: Colegio de México.

Realini, Guadalupe Granero; Barreda, María Pía y Bercovich, Fernando (2018). «La política habitacional en Argentina. Una mirada a través de los institutos provinciales de vivienda». Documentos de Trabajo, 181. Buenos Aires: CIPPEC. Disponible en <https:/www.cippec.org/wp-content/uploads/2019/06/181-CDSDT-La-pol\%C3\%ADtica-habitacional-en-Argentina-Granero-Bercovich-y-Barreda-junio-2016-2.pdf>.

RODRíGUEZ, Jorge (1999). «Información censal relevante para la medición del déficit habitacional». En: CELADE. América Latina: aspectos conceptuales de los censos del 2000. Santiago: Celade.

Rojas, Eduardo y Medellin, Nadine (2011). «Housing Policy Matters for the Poor: Housing Conditions in Latin America and the Caribbean, 1995-2006». IDB Working Paper Series, 289. Washington, DC: Inter-American Development Bank (IDB). Disponible en <http://hdl.handle.net/10419/89104>.

Sergio, Lautaro; Balbuena, Graciela; Thill, María Eugenia; Peralta, Rodrigo y BAMPI, Juan (2016). «Técnicas para la proyección de hogares y su aplicación a la Provincia de Buenos Aires y sus 16 dominios de estimación». Estudios de Población de la Provincia de Buenos Aires, 2 (3).

TORRADO, Susana (2010). «El ajuste argentino en perspectiva histórica». En: TORRADO, Susana (comp.). El costo social del ajuste (Argentina, 1976-2002). Buenos Aires: Edhasa.

United Nations (1973). Manual VII - Methods of Projecting Households and Families. Nueva York: United Nations. 
Vergara Parra, Albano Blas (2017). «El problema habitacional y su evolución reciente en la Región Metropolitana Buenos Aires». Revista Latinoamericana de Población, $11(21), 141-165$. <https://doi.org/10.31406/relap2017.v11.i2.n21.6>

Yépez MartíneZ, Brenda (2011). Proyecciones de hogares una aplicación para Venezuela al horizonte 2021. Doctorado. Universitat Autònoma de Barcelona. Disponible en $<$ https://tdx.cat/handle/10803/32143>.

YéPeZ-MARTínez, Brenda; López-Colás, Julián; Ediev, Dalkhat y Módenes, Juan Antonio (2012a). «Proyecciones de hogares y previsión de demanda de viviendas en Venezuela». En: CAVENAGHI, Suzana (org.). Estimaciones y proyecciones de población en América Latina: desafios de una agenda pendiente. Río de Janeiro: ALAP Editora. YéPEZ-MARTíneZ, Brenda; LóPEZ-ColÁs, Julián; MÓdENES, Juan Antonio y BlANES, Amand (2012b). «Práctica actual de las proyecciones de hogar». En: CAVENAGHI, Suzana (org.). Estimaciones y proyecciones de población en América Latina: desafios de una agenda pendiente. Río de Janeiro: ALAP Editora. 